\title{
Cerebral Artery Blood Flow and Oxygenation in the Frontal Lobe Region in Response to a Judo Chokehold (Shimewaza)
}

\author{
Shukoh Haga ${ }^{1}$, Takuya Sakurai ${ }^{2 *}$, Takafumi Hamaoka ${ }^{3}$, Kazuki Esaki ${ }^{4}$, Kiyomi Ueya ${ }^{5}$, Koji Toshinai ${ }^{6}$, Hiromi \\ Miyazaki $^{7}$, Junetsu Ogasawara ${ }^{2}$, Ken Shirato ${ }^{2}$, Noboru Hashimoto ${ }^{8}$, Toshihito Katsumura ${ }^{3}$, Shoko Nioka ${ }^{9}$, \\ Britton Chance $^{10}$, Iwao Yamaguchi ${ }^{11}$, Takako Kizaki ${ }^{2}$, Hideki Ohno ${ }^{12}$ \\ ${ }^{1}$ Professor Emeritus, Institute of Health Sport Science, University of Tsukuba, Tsukuba, Ibaraki, Japan \\ ${ }^{2}$ Department of Molecular Predictive Medicine and Sport Science, Kyorin University, School of Medicine, Mitaka, Tokyo, Japan \\ ${ }^{3}$ Department of Sports Medicine for Health Promotion, Tokyo Medical University, Shinjuku-ku, Tokyo, Japan \\ ${ }^{4}$ Faculty of Economics, Tokuyama University, Shunan, Yamaguchi, Japan \\ ${ }^{5}$ Professor Emeritus, Faculty of Education and Human Sciences, University of Yamanashi, Kofu, Yamanashi, Japan \\ ${ }^{6}$ Faculty of Wellness, Shigakkan University, Obu, Aichi, Japan \\ ${ }^{7}$ Division of Traumatology, National Defense Medical College Research Institute, Tokorozawa, Saitama, Japan \\ ${ }^{8}$ Department of Judo Therapy, Faculty of Health Sciences, Tokyo Ariake University of Medical and Health Sciences, Koto-ku, Tokyo, Japan \\ ${ }^{9}$ Department of Biochemistry and Biophysics, School of Medicine, University of Pennsylvania, Philadelphia, PA, USA \\ ${ }^{10}$ Professor Emeritus, Department of Biochemistry and Biophysics, School of Medicine, University of Pennsylvania, Philadelphia, PA, USA \\ ${ }^{11}$ Professor Emeritus, Faculty of Medicine, University of Tsukuba, Tsukuba, Ibaraki, Japan \\ ${ }^{12}$ Social Medical Corporation, the Yamatokai Foundation, Higashiyamato, Tokyo, Japan
}

Received: January 27, 2016; Accepted: March 22, 2016; Published: June 06, 2016

*Corresponding author: Takuya Sakurai, Department of Molecular Predictive Medicine and Sport Science, Kyorin University, School of Medicine, 6-20-2 Shinkawa, Mitaka, Tokyo 181-8611, Japan, Tel: +8142247 5511; Fax: +81 42244 4427; E-mail: sakutaku@ks.kyorin-u.ac.jp

\begin{abstract}
Chokeholds (shimewaza) are allowed only in judo competitions They are extremely dangerous and require a high level of technical mastery. However, only a few studies have examined the physiological effects of chokeholds since the Kodokan Judo Institute published the first results in 1958. In the current study, we measured middle cerebral artery blood flow during a chokehold in male members of a university judo club who all had an extensive judo background. Furthermore, we investigated the level of cerebral oxygenation and the blood volume in the frontal lobe of the cerebrum. Middle cerebral artery blood flow was completely cut off when a competitor tapped out just prior to losing consciousness (ochi) from a chokehold. When competitors tapped out due to a chokehold, their heart rates were approximately 10 beats/min higher, and their blood pressure increased by about $10-20 \mathrm{mmHg}$. Oxygenation of the frontal lobe was temporarily decreased prior to tapping out due to a chokehold and tended to slowly return to its previous level after the chokehold was released. In the midst of a chokehold, blood volume initially decreased in half but returned to its previous resting level after release of the chokehold. These findings suggest that the application of a chokehold is extremely dangerous in terms of the hemodynamics of cerebral blood flow even if the individual being choked is barely conscious and able to tap out.
\end{abstract}

Keywords: Judo chokehold; Cerebral; Blood flow; Oxygenation; Tap out; Passes out

\section{Introduction}

Chokeholds (shimewaza) are the only traditional grappling techniques still officially permitted in judo. The allowance of chokeholds makes judo unique among the all of the international and national official combative sports. Chokeholds are a set of techniques with which a competitor uses his forearm, wrist, or judo uniform to constrict the common carotid arteries of his opponent. Therefore, judo chokeholds are extremely dangerous techniques. A chokehold is applied until an opponent "passes out (ochi = asphyxia)" or "taps out (maitta = give up)" by tapping either the body of an opponent or the judo mats (tatami mats). Individuals subjected to a chokehold often lose consciousness. Ascertaining the physiological changes when a competitor loses consciousness is crucial to better understanding the technique and to preventing accidents during judo practice and competitions.

In 1958, researchers specifically chosen by the Kodokan Judo Institute reported "studies in general on choking" in which the physiological responses were monitored by using both X-rays of the heart and electroencephalograms (EEGs) to examine the mechanism of chokeholds from a medical perspective [1-3]. Loss of consciousness as a result of a judo chokehold was reported to be due to a combination of oxygen deficit in the cerebrum and the carotid sinus reflex [1-3]. Moreover, the aforementioned studies revealed that the cardiac silhouette shrinks in terms 
of both its transverse diameter and area as the chokehold continues. The cardiac silhouette is smallest when the opponent loses consciousness, and it returns to its normal size $10 \mathrm{sec}$ after the opponent regains consciousness [2]. Thus, cardiac volume gradually decreases in the midst of a chokehold, and venous return and cardiac output presumably decrease as well. EEGs with waveforms similar to a very brief epileptic seizure were also noted after a chokehold. In addition to problems with consciousness and seizures, signs of sympathetic nerve excitation were also apparent. These changes were presumably due to the effects of tachycardia and hypertension on the carotid sinus reflex [3].

Rodriguez et al. [4] used EEGs and ${ }^{133}$ Xenon inhalation to examine regional cerebral blood flow in 10 judo practitioners before and after they lost consciousness due to a judo chokehold (Kata-juji-jime). They reported that typical delta waves of $3 \mathrm{~Hz}$ were produced primarily in the anterior regions of the brain around $10 \mathrm{sec}$ after a chokehold was applied. Afterwards, the EEG gradually returned to normal. During a chokehold, the regional cerebral blood flow (CBF) decreased in all but one subject. The regional CBF decreased slightly in 4 subjects and markedly in 2 subjects [4]. Raschka et al. [5] used Doppler ultrasound to examine changes in the CBF due to judo cross-choke techniques (Juji-jime). They noted a significant decrease in end-diastolic blood flow in the middle cerebral artery.

Jöbsis [6] first used near-infrared spectroscopy to monitor the oxygen supply to the cerebrum. Later, Chance et al. [7-9] and Hamaoka et al. [10] used near-infrared continuous-wave spectroscopy (NIRcws) as a novel non-invasive technique to examine changes in oxygenation and in hemodynamics in skeletal muscle during human exercise. Although numerous studies of CBF have been conducted [11-14], none have used NIRcws to examine the level of cerebral oxygenation and blood volume to regions of the cerebrum in response to a judo chokehold.

Therefore, in the current study we used Doppler ultrasound to examine the $\mathrm{CBF}$ in the middle cerebral artery during application of a judo chokehold. Specifically, this study focused on whether CBF is maintained at the minimum flow when a judo competitor "tapped out" at the limit of consciousness, i.e., just prior to losing consciousness. In addition, this study used NIRcws to examine changes in blood volume and in resultant oxygenation of the frontal lobe of the cerebrum during the period from application of a chokehold to the recovery phase after its release.

\section{Methods}

\section{Subjects}

This study was conducted with the approval of the ethics committee of the Faculty of Medicine, University of Tsukuba in Japan. Subjects were 4 male judo practitioners who were members of a university judo club. These individuals were extremely healthy and practiced judo almost every day for approximately $3 \mathrm{hrs}$. All subjects had practiced judo for a number of years and were highly proficient and experienced. Table 1 lists the subjects' physical characteristics as well as their age, judo background, and rank (dan). Fully informed consent was obtained from subjects who agreed to participate in this study.

\section{Chokehold protocol}

The chokehold was performed using judo choke techniques (Kata-juji-jime), which constrict the common carotid arteries. Subjects assumed a resting position on the floor (tatami mats), and the chokehold was applied by a professional judo teacher (Figure 1). In the present study, the chokehold was applied until the subject made a sign of "tapped out" which indicated the limit of consciousness. The chokehold was not continued until the subject lost consciousness (ochi = asphyxia); that is, when the subject tapped out, the chokehold was immediately released. The point of this study was to examine the state of CBF and the relationship between cerebral oxygenation and blood volume at the limits of cerebral activity, i.e., at the limits of consciousness. This study took the safety of the participants fully into account.

\section{Measurement of CBF, heart activity, blood pressure, and oxygen saturation}

hiCBF was measured in the middle cerebral artery using a Doppler ultrasound imaging system (SSD-5500, Hitachi Aloka, Japan). Electrocardiograms (ECGs) were also recorded using a Fukuda Cardio Base ECG recorder (FCP-4270, Fukuda Denshi, Japan). Systolic and diastolic blood pressure was monitored with an automated sphygmomanometer (STBT-780, Japan Colling Co. Japan). In addition, oxygen saturation was recorded using a pulse oximeter (Hasimo Rad-5, Fukuda Dens Japan).

\section{Measurement of both blood volume and oxygenation in the cerebral frontal lobe region with NIRcws}

A near-infrared single-distance continuous-wave photometer (HEO-100, Omron Inc., Japan) was used to non-invasively monitor cerebral oxygenation (gauged using oxy-hemoglobin/ myoglobin, oxy-Hb+Mb) and blood volume (gauged using deoxy-hemoglobin/myoglobin, deoxy-Hb+Mb). The logical underpinnings and basic principles of near-infrared spectroscopy have been described in detail by Chance et al. [7-9]. In brief, nearinfrared spectroscopy is performed with probes and a unit that is controlled via a computer. The probes consist of a light source and an optical detector. A pair of 2-wavelength LEDs is used as the light source. The LEDs have maximum wavelengths of 760 and $840 \mathrm{~nm}$. Oxyhemoglobin (gauged using $\mathrm{Hb} / \mathrm{Mb}$ ) and total hemoglobin were calculated using the following formulae [15]:

$$
\begin{aligned}
& \text { Doxy- } \mathrm{Hb}+\mathrm{Mb}=0.66 \mathrm{DOD}_{760}+0.80 \mathrm{DOD}_{840} \\
& \text { Total- } \mathrm{Hb}+\mathrm{Mb}=0.14 \mathrm{DOD}_{760}+0.41 \mathrm{DOD}_{840}
\end{aligned}
$$

$\Delta \mathrm{OD}_{760}$ and $\Delta \mathrm{OD}_{840}$ indicate changes in the optical densities (OD) at 760 and $840 \mathrm{~nm}$, respectively. $\mathrm{Oxy}-\mathrm{Hb}+\mathrm{Mb}$ and $\Delta$ Total$\mathrm{Hb}+\mathrm{Mb}$ indicate changes in the concentrations of oxyhemoglobin/ myoglobin $(\mathrm{Hb}+\mathrm{Mb})$ and total $\mathrm{Hb}+\mathrm{Mb}$, respectively. The light source was located $3.0 \mathrm{~cm}$ from the measurement site.

\section{Statistical analysis}

Data are presented as the mean \pm standard deviation. In addition, Pearson's method was used to examine statistically significant differences with $\mathrm{p}<0.05$. 
Table 1: Ages, length of judo careers, judo rank, and physical characteristics of the subjects.

\begin{tabular}{|c|c|c|c|c|c|c|}
\hline & Age (years) & Career (years) & Judo rank (dan) & Height (cm) & Body mass (kg) & Body mass index \\
\hline Subject 1 & 20 & 11 & 3 & 162.0 & 62.0 & 23.9 \\
\hline Subject 2 & 20 & 10 & 3 & 167.5 & 65.0 & 23.0 \\
\hline Subject 3 & 20 & 9 & 3 & 170.5 & 73.5 & 25.2 \\
\hline Subject 4 & 20 & 12 & 4 & 175.0 & 87.5 & 29.6 \\
\hline Mean & 20.5 & 10.5 & 3.3 & 168.8 & 72.0 & 25.4 \\
\hline (SD) & $(0.6)$ & $(1.3)$ & $(0.5)$ & $(5.5)$ & $(5.5)$ & $(2.4)$ \\
\hline
\end{tabular}

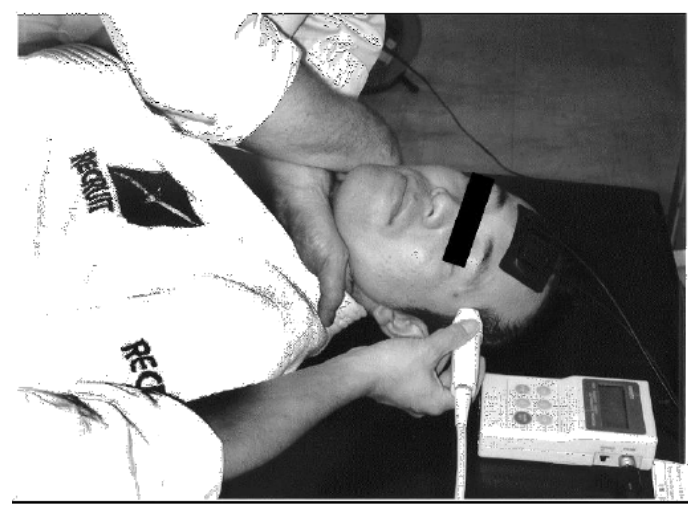

Figure 1: Application of a judo chokehold (Kata-juji-Jime)

\section{Results}

\section{Blood flow in the middle cerebral artery in response to a chokehold}

Doppler ultrasound was used to measure the middle cerebral artery blood flow in response to a chokehold. Results of the chokehold and recovery process for subject T. S. are shown in Figures 2-8: Figure 2 is at rest; Figure 3 is at the start of the chokehold; Figure 4 is $5 \mathrm{sec}$ after the chokehold began; Figure 5 is when the subject tapped out; and Figures 6-8 are $2 \mathrm{sec}$, $15 \mathrm{sec}$, and $30 \mathrm{sec}$ after the chokehold was released. As these figures show, the chokehold promptly resulted in restriction of the middle cerebral artery blood flow. Blood flow decreased markedly after $5 \mathrm{sec}$, and it was completely cut off at the point the when the subject tapped out. Immediately after the chokehold was released, the blood flow increased markedly in the recovery phase. After 15 and $30 \mathrm{sec}$, blood flow tended to return to its previous resting level. This trend was observed in all of the subjects (data not shown). The mean peak flow at rest was 82.8 $\mathrm{cm} / \mathrm{sec}$. Figure 9 shows the changes in peak flow from the start of the chokehold to the point of tapping out and then after the chokehold release. Mean values for the peak flow at each time point are shown. The peak flow disappeared when the subjects tapped out, and then the peak flow was substantially increased at 2 and $5 \mathrm{sec}$ after the chokehold was released. The time from the start of the chokehold to when the subjects tapped out differed somewhat depending on the subject but was approximately 7-15 sec, with a mean of $10.75 \mathrm{sec}$ (Table 2). When the subjects tapped out, the mean $\mathrm{O}_{2}$ saturation was $89.8 \%$ (Table 3).

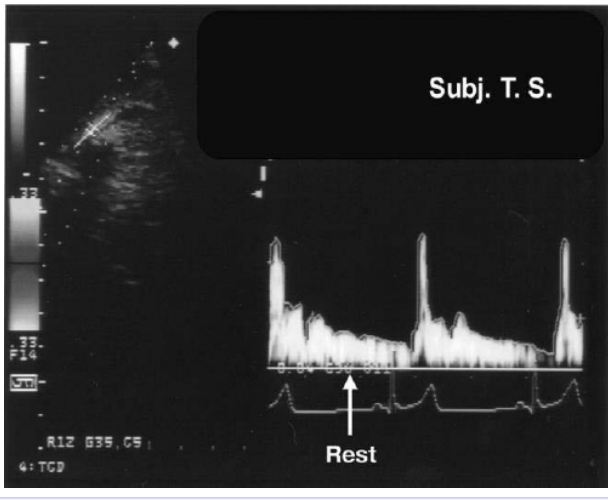

Figure 2: Peak blood flow in the middle cerebral artery at rest.

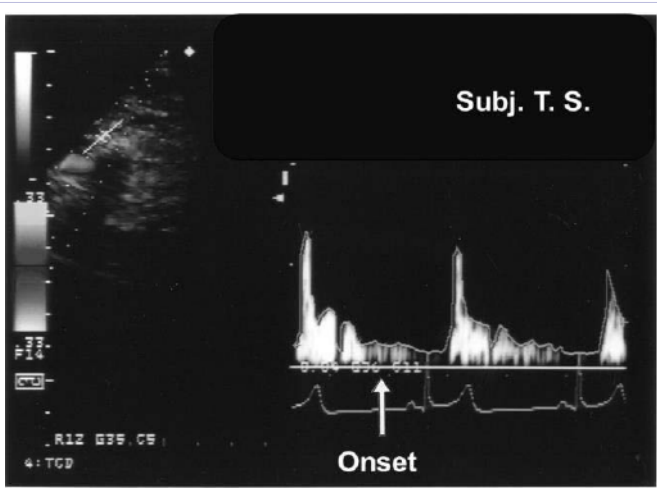

Figure 3: Peak blood flow in the middle cerebral artery at the onset of a chokehold.

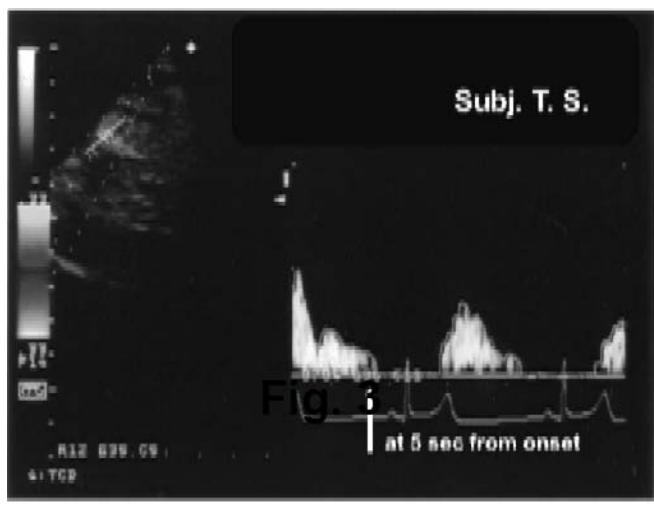

Figure 4: Peak blood flow in the middle cerebral artery at 5 sec after the onset of a chokehold. 


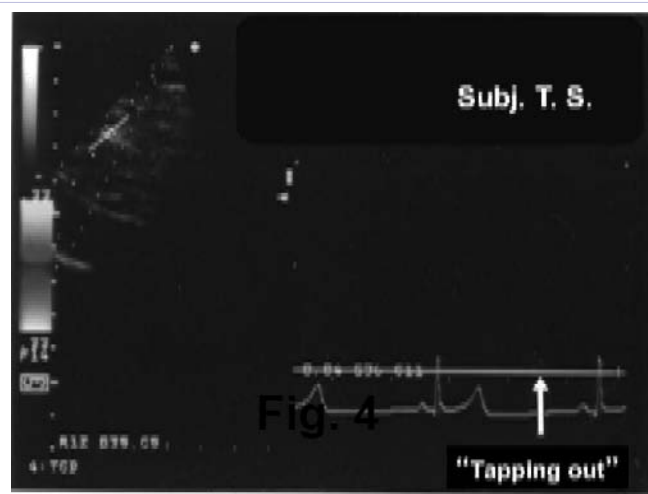

Figure 5: Peak blood flow in the middle cerebral artery at the point of tapping out from a chokehold.

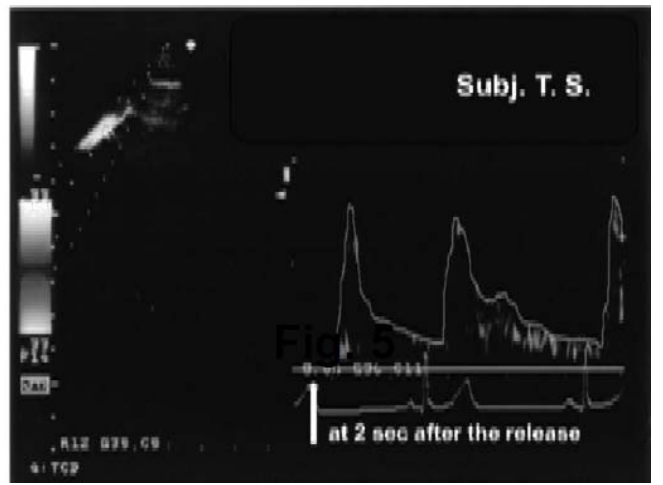

Figure 6: Peak blood flow at 2 sec after the release of a chokehold.

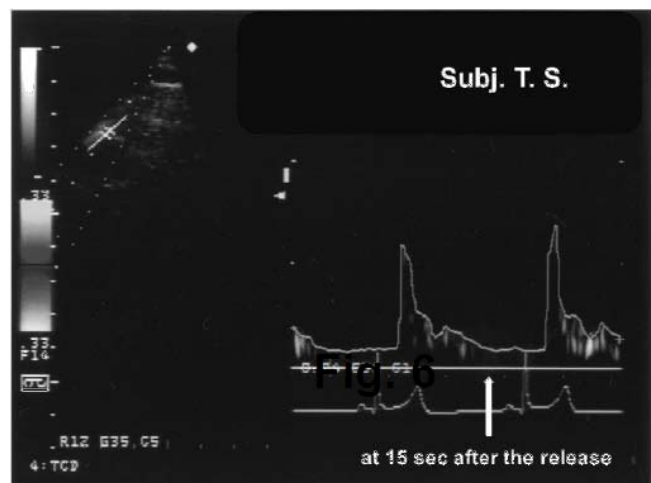

Figure 7: Peak blood flow at 15 sec after the release of a chokehold.

\section{Blood pressure and heart rate during a chokehold}

Changes in both heart rate and blood pressure when a chokehold was applied are shown in Figure 10. Since the subjects were current judo athletes who practiced approximately 3 hours per day, their physical health was reflected in their mean heart rate in a resting supine position at about 43 beats/min, which increased to about 50 beats/min when the subjects tapped out. One minute after the chokehold was released, the heart rate returned to about 45 beat $/ \mathrm{min}$. The mean blood pressure in a resting supine position was $122 / 60 \mathrm{mmHg}$. When the subjects

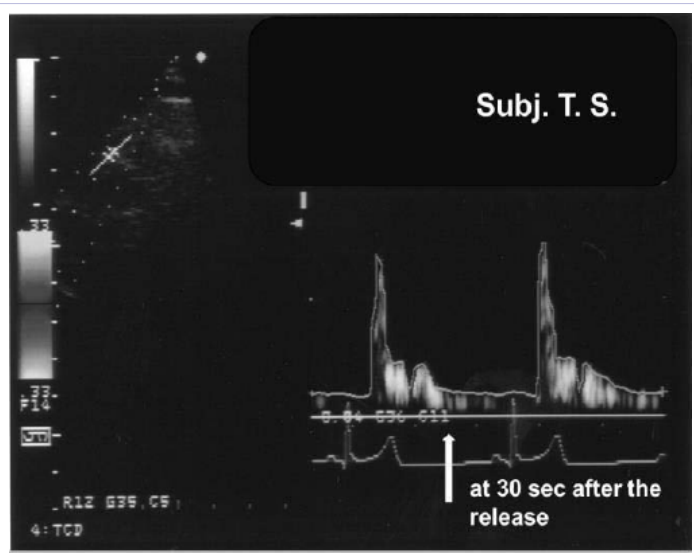

Figure 8: Peak blood flow at $30 \mathrm{sec}$ after the release of a chokehold.

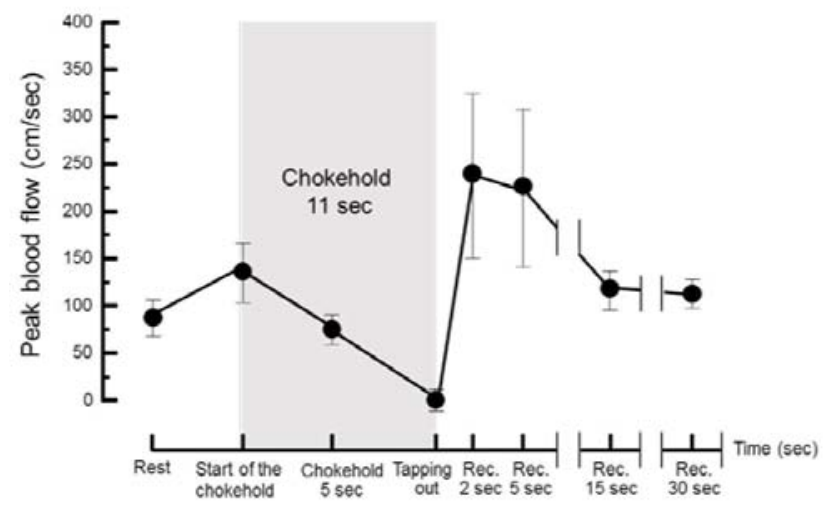

Figure 9: Peak blood flow in the middle cerebral artery during the application of a chokehold and in the recovery phase.

The mean $\pm \operatorname{SD}(n=4)$ is shown.

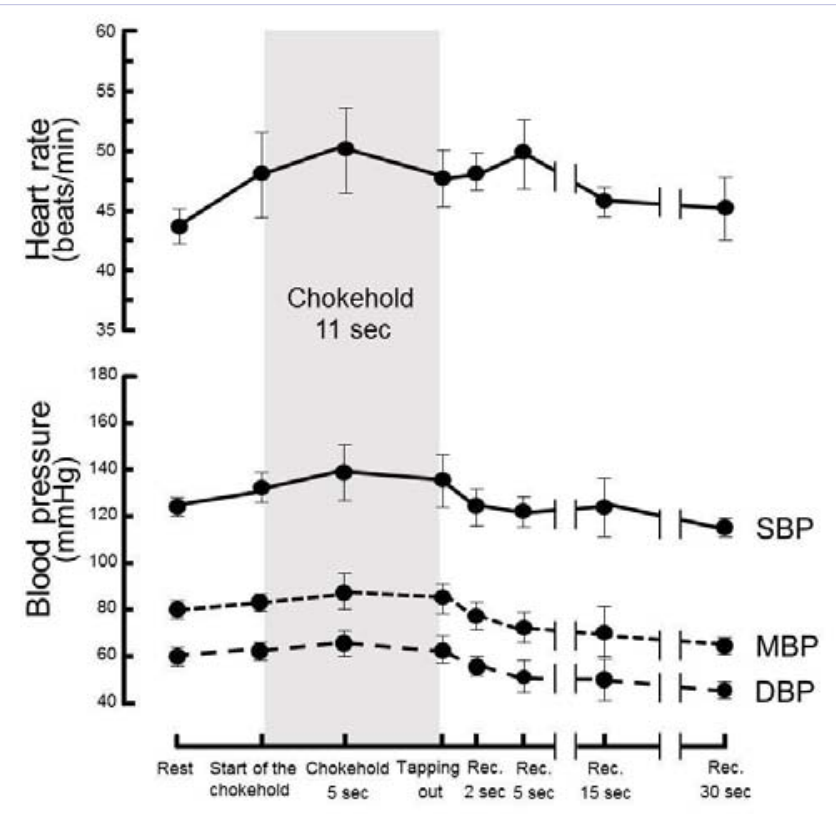

Figure 10: Blood pressure and heart rate during a chokehold and in the recovery phase. The mean $\pm \operatorname{SD}(n=4)$ is shown. 
Table 2: Time of the chokehold from onset to tapping out.

\begin{tabular}{|c|c|c|c|c|c|c|}
\hline Subject & 1 & 2 & 3 & 4 & Mean & SD \\
\hline Time(sec) & 7 & 12 & 9 & 15 & 10.8 & 3.5 \\
\hline
\end{tabular}

Table 3.0xygen saturation at the point of tapping out of a chokehold.

\begin{tabular}{|c|c|c|c|c|c|c|}
\hline Subject & 1 & 2 & 3 & 4 & Mean & SD \\
\hline $\begin{array}{c}\text { Oxygen saturation } \\
(\%)\end{array}$ & 88 & 90 & 92 & 89 & 89.8 & 1.7 \\
\hline
\end{tabular}

tapped out, the mean blood pressure rose to $137 / 62 \mathrm{mmHg}$. One minute after the chokehold was released, the blood pressure returned to the resting level of $120 / 50 \mathrm{mmHg}$.

The effect of a chokehold on the blood volume and on oxygenation in the frontal lobe region of the cerebrum using NIRcws

Changes in oxygenation and in blood volume due to a chokehold applied to subject Y. I. are shown in Figure 11, and similar changes in subject T. S. are shown in Figure 12. These figures indicate that oxygenation in the brain decreased abruptly when the chokehold was applied and reached its lowest level when the subject tapped out. When the chokehold was released, however, oxygenation gradually increased and plateaued at a level about half of that at rest. Oxygenation then tended to slowly return to its previous level. Thus, the return of oxygen levels to the resting level took some time. When subjects tapped out, the mean OD was -0.022 (Table 4). The blood volume similarly decreased abruptly when the chokehold began. Nevertheless, although the time before tapping out varied among the subjects, the blood volume returned to its resting level in about half the time that the chokehold took to apply. In other words, oxygenation in the brain temporarily decreases until an individual reaches the point of tapping out. By contrast, blood volume returns to its resting level as the chokehold is approximately $50-60 \%$ complete, i.e., prior to the individual tapping out.

\section{Discussion}

Chokeholds in judo are traditional martial arts techniques with a long history in Japan. These techniques can directly affect human life and death, and among the modern international and

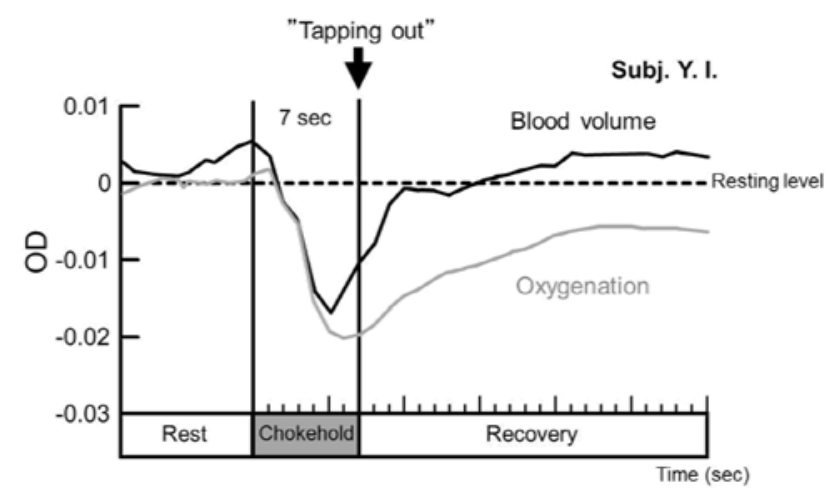

Figure 11: Oxygenation and blood volume by NIR $\mathrm{CWS}_{\text {in }}$ the frontal lobe during the application of a chokehold on subject Y.I.

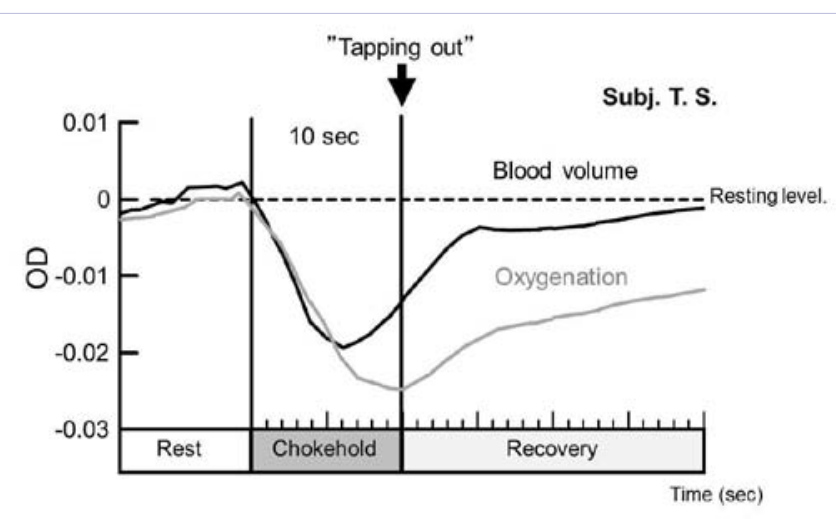

Figure 12: Oxygenation and blood volume by NIR $_{\text {CwS }}$ at the frontal lobe during the application of a chokehold on subject T.S.

Table 4: Optical density values at the point of tapping out of a chokehold.

\begin{tabular}{|c|r|r|r|r|c|c|}
\hline Subject & 1 & 2 & 3 & 4 & Mean & SD \\
\hline OD & -0.020 & -0.024 & -0.024 & -0.020 & -0.022 & 0.002 \\
\hline
\end{tabular}

official national sports chokeholds are allowed only in judo. There are numerous types of chokeholds, among which Kata-juji-jime is typical. This technique involves holding on tightly to the collar of the opponent's judo jacket and compressing both common carotid arteries with substantial pressure from the outside. This constricting technique cuts off blood flow without causing pain. In judo practice and matches, the chokehold is usually applied until the opponent taps out or loses consciousness. One hypothesis in this study was that a minimum blood flow would be maintained, despite a massive decrease in the $\mathrm{CBF}$ as a way for the body to preserve life, even when a chokehold brought a subject to the brink of either losing of consciousness or stupor. That is, the blood flow would presumably be maintained, albeit at a minimal level, so that an individual could tap out before completely losing consciousness. In anatomical terms, the right and left vertebral arteries arise from the subclavian arteries deep in the neck and join to form the basilar artery that connects to the arterial circle of the cerebrum. These arteries were assumed to preserve some blood flow even if the common carotid arteries were constricted. The common carotid arteries bifurcate into the internal carotid arteries, which in turn branch into the middle cerebral artery. As indicated by the hemodynamics of the middle cerebral artery and peak flow, blood flow abruptly decreased 5 sec after a chokehold began. Notably, blood flow in the common carotid arteries was cut off just prior to the subject ultimately losing consciousness; 
that is, the CBF has already stopped when an individual remains barely conscious when tapping out. In previous studies of chokeholds, Ikai et al. [1] reported that the time prior to an individual completely losing consciousness was 10-12 sec, while Suzuki et al. [3] reported that it was 8-14 sec. One study that involved applying a chokehold until the individual passed out according to a sphygmomanometer cuff reported that the time prior to loss of consciousness was 12-15 sec. [3]. The current study did not involve applying a chokehold until the subject completely lost consciousness, and the chokehold was released at the same time the individual tapped out. The time from when the chokehold began until the subject tapped out was 7- $15 \mathrm{sec}$ (mean time of approximately $11 \mathrm{sec}$ ) when the subject was in a supine position and not resisting, which is consistent with that in the aforementioned studies. Thus, the CBF is completely cut off when an individual taps out due to a chokehold, which is almost at the same time in which they lose consciousness. If there is even a slight delay in the time from when an individual taps out until the chokehold is released, the individual could be brought close to death.

The current study used Doppler ultrasound. Ultrasonic waves were verified as being correctly directed at the blood vessel being imaged. Typically, the blood flow in ultrasound images is calculated as a steady state assuming that blood vessels are a perfect cylinder. Like the current study, a study by Raschka et al. [5] used Doppler imaging and cited a peak flow of $85.3 \mathrm{~cm} /$ sec. Similarly, the current study noted a peak flow at rest of $82.8 \mathrm{~cm} / \mathrm{sec}$. However, a look at the flow during a chokehold indicates that blood vessels deform considerably as a result of strong external pressure and ultimately close completely. Thus, the peak flow at different times does not accurately reflect flow at certain levels because of the changes in the shape of the blood vessels. In addition, various other factors may considerably affect blood flow, such as differences in externally applied pressure, the time prior to a tap out, the thickness and elasticity of a subject's vascular walls, and the size of the vascular lumen. The peak flow at 2 and $5 \mathrm{sec}$ after a chokehold was released was about $20 \%$ greater than that at the resting level, because large quantities of blood had pooled due to occlusion of the common carotid arteries. Soon after the chokehold was released, the vascular diameter increased substantially from the diameter at rest, producing a large contractile force in response. Moreover, blood vessels are likely to expand due to the increases in the arterial $\mathrm{CO}_{2}$ concentration [16]. Thus, the shape of the blood vessels differed widely at rest, during a chokehold, and after a chokehold was released. Evaluating the peak flow with the similar changes in vascular morphology is currently impossible, but the peak flow data from this study are still vital to determining blood flow in the middle cerebral artery during a chokehold.

Changes in both heart rate and blood pressure were examined from the start of a chokehold until a subject tapped out and after the chokehold was released. When the substantial external pressure of the chokehold was applied to the neck and the subject tapped out, the subject's heart rate increased by approximately $10-15$ beats $/ \mathrm{min}$. At the same time, the subject's systolic blood pressure increased by around $10-20 \mathrm{mmHg}$, and the subject's diastolic blood pressure increased $10 \mathrm{mmHg}$. After the chokehold was released, the subject's heart rate and blood pressure returned to their resting levels. These findings are generally in agreement with that of previous studies [1-3]. The cardiovascular response to a chokehold can be considered in terms of the mechanism of the carotid sinus baroreflex $[17,18]$. Kata-juji-jime compresses and constricts the common carotid arteries, which substantially compresses the common carotid sinus at the root of the internal carotid artery at the same time. Therefore, occlusion of the common carotid artery increases both blood pressure and heart rate. However, when the walls of the carotid sinus stretch, baroreceptors in those walls sense the stretching and excite the cardiac branches of the vagus nerve in response. Simultaneously, the sympathetic activity on both the heart and blood vessels is inhibited. As a result, heart rate, cardiac output, peripheral resistance, and blood pressure decrease. Moreover, electrical stimulation of the carotid sinus has similarly demonstrated evidence of a carotid sinus baroreflex $[17,18]$. This reflex decreases both blood flow and blood pressure, potentially causing a loss of consciousness, syncope, and cardiac arrest. Nevertheless, the heart rate and arterial blood pressure both increase just prior to either a tap out or loss of consciousness because of baroreceptors in the carotid sinus and aortic arch, which are nerves that regulate blood pressure. When blood pressure drops, inhibition of the cerebrovascular center in the medulla oblongata consequently decreases, and sympathetic nerve impulses increase, helping restore blood pressure to its previous level $[18,19]$. Thus, the heart rate and blood pressure increase even though the carotid sinus baroreceptors are excited $[18,19]$. In addition to this mechanism, inhibited blood flow excites chemo receptors in the carotid body, causing an $\mathrm{O}_{2}$ deficit (circulatory hypoxia = anoxia). Increased chemoreceptor activity causes a pressor reflex that is assumed to be associated with an elevated heart rate and elevated blood pressure $[18,19]$. Furthermore, increases in the $\mathrm{CO}_{2}$ levels in the blood are thought to bring about expansion of the blood vessels $[16,18,19]$. When Ganong [16] clamped the right and left common carotid arteries below the carotid sinus, the pressure in the sinus decreased, systemic blood pressure rose, and the heart rate increased. However, Ganong [16] described the effect as minimal, because although baroreceptors in the common carotid sinus and aortic arch act together, aortic arch baroreceptors probably still function normally when the common carotid arteries are clamped below the carotid sinus. Studies by Ikai et al. [1] and Suzuki et al. [3] supported the view that a chokehold increases both heart rate and blood pressure from the perspective of the carotid sinus baroreflex. Takagi and Nagasaka [20] stated that the pressure in the carotid sinus decreased as a result of compression of the common carotid arteries. In response, the heart rate, pulse pressure, and blood pressure in the brachial artery all increased.

No previous studies have used NIRcws to examine changes in brain oxygenation with a judo chokehold. The current study specifically examined both oxygenation and blood volume in the frontal lobe region of the brain. The blood volume was at its lowest level at midway from the start of the chokehold until the individual tapped out (around 5-6 sec after the chokehold 
began). After release of the chokehold, the blood volume then gradually returned to its level at rest. This pattern was evident in all subjects. Oxygenation temporarily decreased up to the time of tap out, i.e. on the brink of consciousness. The mean $\mathrm{OD}$ at this point was -0.022 in the 4 subjects. About 5-6 sec after a chokehold is released, oxygenation plateaus at a level of about half of that at rest and does not quickly return to its resting level. Instead, the recovery of oxygenation in the brain is delayed even after blood flow in the middle cerebral artery has recovered. Therefore, oxygenation in the brain appears to take a relatively long time to return to its resting level, although there are individual differences in the time needed to recover. These findings can be used to better understand oxygenation in the brain resulting from a judo chokehold. Blood flow to the cerebrum reaches the frontal lobe through the common carotid artery, internal carotid artery, and middle cerebral artery. Therefore, a cutoff of blood flow in the common carotid artery due to a judo chokehold leads to a loss of cerebrum functions, such as the conscious, memory, and judgment [19]. Although blood volume quickly decreases when the chokehold begins, blood volume returns in about half of the time that elapsed from the start of the chokehold until the individual taps out. Therefore, in response to the crisis of reduced blood flow in the common carotid arteries that is cut off or restricted by the chokehold, residual blood volume from sites other than the frontal lobe of the cerebrum is thought to contribute blood to preserve life [19]. The circle in Willis has markedly less blood flow than that in the basilar artery. Furthermore, the basilar artery joins the posterior cerebral artery, and the combined blood flow circulates in the cerebellum, brain stem, and occipital lobe [19]. Therefore, it may be very difficult for the individual to function when the blood flow to the posterior cerebral artery is redirected to compensate for the reduced flow in a chokehold. By contrast, oxygenation temporarily decreases until an individual taps out, probably because brain neuronal cells continue to take up $\mathrm{O}_{2}$ in the form of $\mathrm{Oxy}-\mathrm{Hb}+\mathrm{Mb}$, and neural activity is maintained even while the blood supply is substantially restricted. However, oxygenation does not readily return to its resting level in the recovery phase after a chokehold is released. Therefore, once the functioning of brain cells has been maintained to the limit, $\mathrm{Hb}+\mathrm{Mb}, \mathrm{O}_{2}$ binding ability in braincells, and recovery of consciousness are thought to be delayed even if the $\mathrm{CBF}$ is restored. Consequently, brain activity may take some time to recover. These phenomena can also be explained in terms of reactive $\mathrm{O}_{2}$ species. Once a chokehold is released, large quantities of reactive $\mathrm{O}_{2}$ species would be generated in the brain if oxygenation abruptly returned to its resting level, causing serious damage to brain cells and oxidation of blood vessels in the brain [21]. This phenomenon could cause brain dysfunction similar to that during reperfusion after ischemia following acute myocardial infarction. The body's defensive response is to inhibit or to avoid an abrupt generation of reactive $\mathrm{O}_{2}$ species, which is presumably why oxygenation recovers at a slower rate.

The relationship between $\mathrm{O}_{2}$ saturation and the OD for cerebral oxygenation during a tap out was also assessed. When a subject tapped out due to the chokehold in this study, the initial level of
$\mathrm{O}_{2}$ saturation was the level just prior to loss of consciousness, i.e., asphyxia. A previous study [1] that measured $\mathrm{O}_{2}$ saturation in the ear lobe reported that $\mathrm{O}_{2}$ saturation was $82-85 \%$ when an individual lost consciousness. Assuming that $\mathrm{O}_{2}$ saturation at rest is $98 \%$, then a decline of $13-16 \%$ results in cerebral oxygen deprivation and may lead to a loss of consciousness. According to the present NIRcws results, the OD for oxygenation in the brain was -0.022 during a tap out. Assuming the individual completely loses consciousness, the OD would be approximately -0.030 . In either event, examining cerebral oxygen deprivation in terms of the relationship between $\mathrm{O}_{2}$ saturation and oxygenation (gauged using the OD) is a topic for future study.

The current results indicate that when a chokehold is applied, circulation is cut off, which is extremely dangerous in terms of the hemodynamics of CBF. This is true even if a competitor has sufficient brain activity to remain conscious enough to tap out. The brain is exquisitely sensitive to changes in oxygen dynamics, such that if blood flow to the brain is cut off, consciousness is lost within 10 seconds. In particular, sensitivity for hypoxia in the cerebral cortex is suggested to be higher than that in the brain stem. Moreover, even if brain functions are partly recovered after a hypoxic state, mental functions and intelligence do not return as quickly to their former state [16]. Although chokeholds are permitted by the rules during judo competitions, whether or not they should continue to be permitted in light of their physical effects relative to their benefit must be examined in the future. Being subjected to a chokehold reduces brain activity during growth and development in preadolescence, adolescence, and adulthood. Rendering an individual unconscious for a prolonged period could lead to accidental death, so such actions should probably be prohibited in principle. Assuming, however, that chokehold techniques are permitted in combative sports in the future and then the use of those techniques should only be permitted by adult athletes. During daily practices, coaches must provide adequate monitoring and supervision. In addition, frequently applying a chokehold to the same individual should be strictly prohibited. During a match, an athlete need not continue competing until his opponent taps out to indicate a clear winner and loser. Instead, the referee should declare victory when an athlete has assumed a position where a chokehold technique can be fully applied and that technique will be readily effective but before his opponent taps out due to the chokehold. This issue is important from medical, health, and educational perspectives. Moreover, the risks of chokeholds should be fully considered in future judo competitions overseas.

\section{Acknowledgments}

This work was partially supported by Grants in Aid for Specific Project Research from the Ministry of Education, Culture, Sports, Science and Technology of Japan.

\section{References}

1. Ikai M, Ishiko T, Ueda G, et al. Physiological Studies on "Choking" in Judo. Part 1: Studies in General. Bulletin of the Association for the Scientific Studies on Judo, Kodokan. Report I. 1958; 1-12.

2. Ikai M, Yamakawa J, Ogawa S, Akutsu K, Masuda M, Matsumoto Y. Physiological studies on "Choking" in Judo. Part II: X-ray Observations on the heart. Bulletin of the Association for the scientific Studies on 
Judo, Kodokan. Report I. 1958; 13-22.

3. Suzuki K. Medical Studies on "Choking" in Judo with Special Reference to Electro-encephalographic Investigation. Bulletin of the Association for the Scientific Studies on Judo, Kodokan. Report I. 1958; 23-48.

4. Rodriguez G, Francione S, Gardella M, Marenco S, Nobili F, Novellone G, et al. Judo and choking: EEG and regional cerebral blood flow finding. J Sports Med Phys Fitness. 1991;31(4):605-610.

5. Raschka C, Stock A, Brunner K, Witzel K. Investigation on changes of intracranial blood flow velocity induced by choking in Judo (Shime Waza) by means of transcranial Doppler sonography. Dtsch Z Sportmed. 1996; 47: 393-8.

6. Jöbsis FF. Noninvasive infrared monitoring of cerebral and myocardial oxygen sufficiency and circulatory parameters. Science. 1977; 198(4323):1264-1267.

7. Chance B. Rapid and sensitive spectrophotometry. I. The accelerated and slopped-flow methods for the measurement of the reaction kinetics and spectra of unstable compounds in the visible region of the spectrum. Rev Sci Instr. 1951;22:619-627.

8. B Chance, J S Leigh, Jr, B J Clark, J Maris, J Kent, S Nioka, et al. Control of oxidative metabolism and oxygen delivery in human skeletal muscle: a steady-state analysis of the work/energy cost transfer function. Proc Natl Acad Sci USA. 1985;82(24):8384-8388.

9. Chance B, Dait MT, Zhang C, Hamaoka T, Hagerman F. Recovery from exercise-induced desaturation in the quadriceps muscles of elite competitive rowers. Am J Physiol. 1992; 262(3):C766-775.

10. Hamaoka T, Albani C, Chance B, Iwane H. A new method for the evaluation of muscle aerobic capacity in relation to physical activity measured by near-infrared spectroscopy. Med Sport Sci. 1992;37:421429.

11. Ferrari M, Zanette E, Giannini I, Sideri G, Fieschi C, Carpi A. Effects of carotid artery compression test on regional cerebral blood volume, hemoglobin oxygen saturation and cytochrome-C-oxidase redox level in cerebrovascular patients. Adv Exp Med Biol. 1986;200: 213-221.

12. Wyatt JS, Cope MC, Delpy DT, Wray S, Reynolds EO. Quantification of cerebral oxygenation and hemodynamics in sick newborn infants by near infrared spectroscopy. Lancet. 1986;2(8515):1063-1065. doi: 10.1016/S0140-6736(86)90467-8.

13.Villringer A, Planck J, Stodieck S, Botzel K, Schleinkofer L, Dirnagl U. Noninvasive assessment of cerebral hemodynamics and tissue oxygenation during activation of brain function in human adults using near infrared spectroscopy. Adv Exp Med Biol. 1994;345:559-565.

14.Hock C, Muller-Spahn F, Schuh-Hofer S, Hofmann M, Dirnagl U, Villringer A. Age dependency of changes in cerebral hemoglobin oxygenation during brain activation: A near-infrared spectroscopy study. J Cereb Blood Flow Metab. 1995;15(6):1103-1108. doi: 10.1038/jcbfm.1995.137.

15. Shiga T, Yamamoto K, Tanabe K, Nakase Y, Chance B. Study of an algorithm based on model experiments and diffusion theory for a portable tissue oximeter. J Biomed Opt. 1997;2(2):154-161. doi: $10.1117 / 12.268963$.

16. Ganong W. Review of Medical Physiology. 7th ed. Los Altos: Lange Medical Publication; 1975.

17. Robert M, Matthew N. Cardiovascular Physiology. 2nd ed. St. Louis: The C. V. Mosby company; 1972.

18. Iriuchijima J. Circulation reflex: Introduction of Circulation Physiology. Tokyo: Corporation Medical Publisher; 1966. p. 115-23.

19. Toida N, Uhizono K. Nerurogenec regulation of circulation, Text Book of Modern Physiology II. 4th ed. Tokyo: IGAKUSHOINN Ltd.; 1975. p. 277-300.

20.Takagi K, Nagasaka T. Muscular Circulation Japanese Handbook of Physiology III. 1st ed. Tokyo: IGAKUSHOINN Ltd.; 1969. p. 1006-15.

21. Chen H, Yoshioka H, Kim GS, et al. Oxidative stress in ischemic brain damage: mechanisms of cell death and potential molecular targets for neuroprotection. Antioxid Redox Signal. 2011;14(8):1505-17. doi: 10.1089/ars.2010.35762011. 